\title{
Disorders of carbohydrate absorption in childhood
}

\author{
CHARLOTTE M. ANDERSON \\ From the University of Birmingham, Institute of Child Health, Francis Road, Birmingham
}

Until the last decade emphasis was placed on fat malabsorption as the principal dietary cause of persistent diarrhoea in childhood. That abnormalities of the absorption of sugar could be responsible had not been widely realized and it is only 12 years since Holzel, Schwarz, and Sutcliffe (1959) in Manchester described familial congenital lactose intolerance; 11 years since Weijers, van de Kamer, Mossel, and Dicke (1960) described fermentative diarrhoea due to dietary sucrose; and nine years since Anderson, Messer, Townley, Freeman, and Robinson (1962) gave the first demonstration that the disaccharidasessucrase and isomaltase-were not present in the small-intestinal mucosa of two siblings who presented with persistent watery diarrhoea which disappeared on withdrawing sucrose from the diet. However, now we recognize a wide variety of primary and secondary types of sugar intolerance involving both disaccharides and monosaccharides and these are outlined in Table $\mathbf{I}$.

\begin{tabular}{ll}
\hline Disaccharides & Monosaccharides \\
\hline $\begin{array}{l}\text { Primary } \\
\text { Sucrase-isomaltase deficiency }\end{array}$ & $\begin{array}{l}\text { Glucose-galactose } \\
\text { malabsorption } \\
\text { (fructose tolerated) }\end{array}$ \\
Lactase deficiency & $\begin{cases}\text { Infant } \\
\text { Adult }\end{cases}$ \\
Mecondary & $\begin{array}{l}\text { Lactase } \\
\text { deficiency } \\
\text { Deficiency } \\
\text { of all disaccharidases }\end{array}$ \\
\hline
\end{tabular}

Table I Types of sugar intolerance in childhood

A glance into the past is always salutary, and on perusing the paediatric literature of the earlier part of this century, amongst German publications on infant feeding, one comes across a number of references to diets which excluded certain sugars. John Howland, the first professor of paediatrics at Johns Hopkins University, Baltimore, chose Germany for his postgraduate experience, and perhaps this is why he became interested and aware of the possibilities of abnormalities in the digestion and absorption of dietary sugars and gave a paper entitled 'Prolonged intolerance to carbohydrates' as his presidential address to the American Paediatric Society in 1921. In this talk he gives a remarkably clear clinical description of the symptoms of sugar intolerance and malabsorption as we know them today. He also recognizes that there are primary $\vec{A}$ types and others secondary to such disorders as 을 gastroenteritis, and he realizes that in some babies only disaccharides give trouble but in others a more severe intolerance involving all sugars, even monosaccharides, can occur. He deduces that the symptom of watery diarrhoea is associated with the osmotic pull of the unabsorbed sugar, and sums up by stating that little more will be known about these condition until methods have been evolved to demonstrate the enzymes in the small intestine that are responsible for digesting and absorbing sugars. In this prediction he was entirely correct but probably did not think that it would be about 40 years before knowledge outlined by the previous speaker (p. 10) would be available so that the types of disorder referred to in Table I can now be precisely identified.

Symptoms and Clinical Pattern of Sugar Intolerance

Sugars should be quickly absorbed in the upper small intestine. However, if they are not absorbed and remain in the intestinal lumen osmotic diarrhoea will result and the sugars are in part excreted unchanged in the faeces and in part undergo bacterial degradation causing further fermentative diarrhoea. Thus the symptom of sugar malabsorption is diarrhoea. The osmotic component of the diarrhoea depends for its severity on the concentration and therefore osmotic pressure of the unabsorbed sugar in the lumen. Fluid and electrolytes are drawn into the gut, peristalsis is stimulated by distension, and watery diarrhoea results. As a result of fermentation the stools become acid, with a high concentration of lactic acid; they are passed with gas from further fermentation of lactic acid to $\mathrm{CO}_{2}$ and water. Thus the stools are watery, acid, with a $p H$ less than $5 \cdot 5$, irritating to the buttocks, frequent, and noisily 
passed. In the absence of such stools, the diagnosis cannot be upheld in childhood. In small infants one must take care to collect the stools on a nonabsorbent napkin or they may be mistaken for urine.

The diagnosis is suspected from the typical history of persistent fluid fermentative stools and the fact that the onset is related either to the introduction of, or changes in, the type of sugar in the diet, or to the presence of some other gastrointestinal illness. Thus the clinical history of a suspected case must contain a detailed dietary history, particularly in regard to sugars added to feeds, and a knowledge of the type of carbohydrate present in the various milk preparations fed to infants. In the primary types symptoms will either be present from birth, as in lactose intolerance and glucose-galactose malabsorption, in sucrase isomaltase deficiency when the milk feeding contains sucrose, or when mixed feeding is introduced.

As a result of osmotic diarrhoea there is excess fluid and electrolyte loss and therefore dehydration may supervene. Intestinal hurry may result in accompanying steatorrhoea and further calorie loss, and the weight may remain stationary or go down. On the other hand a compensating high intake of fluid and calories may balance the losses and there may be little or no failure to thrive or constitutional symptoms. Fermentation usually causes gaseous distension and borborygmi which sometimes lead to colicky abdominal pain-more noticeable in the older child.

The symptomatology of sugar intolerance varies considerably with age. Diarrhoea is much more severe in the young infant than in the toddler or older child and especially in the adult in whom the symptoms may be confined to abdominal discomfort or colicky pain and borborygmi. There are several explanations for this. First the load of sugar taken by a young infant in milk feeds is large and the osmotic component of diarrhoea therefore plays a predominant role. Older children will often have a lower intake of carbohydrate as disaccharide or monosaccharide and a higher intake as starch and, as a consequence, symptoms are mild and more difficult to diagnose. In the adult there may be little or no diarrhoea unless a challenging dose of the particular sugar is taken. The offending sugars are normally taken in relatively lesser loads and the adult colon appears to reabsorb fluid entering from the small bowel better than the infant colon.

\section{Diagnosis of Sugar Intolerance}

That diarrhoea may be due to malabsorption of sugar can be demonstrated by several methods. These vary from simple bedside tests to more complex clinical and laboratory techniques. $p \mathrm{H}$ OF STOOL

This is a simple bedside procedure. A pH of below 5.5 indicates fermentative diarrhoea and is a reflection of the low molecular weight fatty acids, particularly lactic acid (Weijers, van de Kamer, Dicke, and Ijsseling, 1961).

DEMONSTRATION OF REDUCING SUBSTANCES IN THE STOOL

This can be done $(a)$ by Clinitest (Kerry and Anderson, 1964), (b) by chromatography, or (c) by estimating the total reducing substances.

It must be emphasized that the stool tested for reducing substances must include any fluid portion. It is valueless to test a portion of solid stool removed from a napkin into which the fluid has soaked. It must also be emphasized that the stool is either tested freshly at the bedside, or quickly transported to the laboratory where it should be frozen if testing is to be delayed. Otherwise further fermentation will occur and reducing substances disappear.

It should also be realized that only reducing sugars can be shown up by Clinitest, and if the presence of sucrose is suspected in the stool it should be tested before and after hydrolysis with dilute $\mathrm{HCl}$.

Minor quantities of reducing substance (less than $200 \mathrm{mg} \mathrm{\%}$ ) are present in many normal stools. Therefore Clinitest should only be considered significant if $0.5 \%$ or over. Chromatography is useful for demonstrating the individual sugars present in the stool, but too sensitive for assessing clinical significance. In clinical practice it is rarely necessary to estimate total reducing substance.

DEMONSTRATION OF HIGH LACTIC ACID CONTENT

It is necessary to collect stools for 24 hours and each stool should be frozen shortly after being passed. The test (Weijers et al, 1961) is arduous and slow and now rarely used in clinical practice.

\section{SUGAR LOADING TESTS}

These can be followed $(a)$ by rise in blood levels or $(b)$ by stimulation of diarrhoea so that stools contain excess reducing substances.

By this means individual disaccharides or monosaccharides may be given as challenging doses. Many favour estimation of blood levels and consider that a rise of less than $30 \mathrm{mg} \%$ during two hours indicates sugar malabsorption. In childhood blood levels are unreliable. The dose is often unpalatable to babies or infants and may lead to vomiting or slowed stomach emptying. It may also evoke an emotional response, leading to rise in blood sugar by production of adrenaline. 
A loading dose, or to be certain, two consecutive doses, accompanied by careful observation and collection of the stools for six to eight hours afterwards, will demonstrate the passage of a fluid stool positive for reducing substances if sugar intolerance is present.

THERAPEUTIC EXCLUSION OF DISACCHARIDES AND/OR MONOSACCHARIDES

Complete cessation of symptoms and disappearance of reducing substances from the stools indicates intolerance to that particular sugar and is seen in primary sugar intolerance. Secondary types may show great reduction in diarrhoea and loss of reducing substances but, as in coeliac disease, not completely normal stools.

DIRECT MICROCHEMICAL ASSAY OF DISACCHARIDASE ACTIVITIES

The assay is done on the small-intestinal mucosa obtained by peroral biopsy (Dahlqvist, 1964; Messer and Dahlqvist, 1966). This test is important in the final diagnosis of primary sugar intolerance but of lesser importance in secondary varieties. Specimens should be taken from the upper jejunum rather than from the duodenum, and with the exception of very low or negative disaccharidase levels, the absolute values have less diagnostic importance than have the ratios between the various activities, eg, a ratio of sucrase to lactase greater than 1 .

It must be realized, especially in the secondary types, that one small biopsy is not necessarily representative of the whole small intestine and, for instance, in coeliac disease the proximal intestine may be more abnormal than the distal and the disaccharidase levels in a single biopsy in the upper jejunum may therefore be misleading. Low disaccharidase levels in one specimen are not important in the absence of symptoms of sugar malabsorption.

BARIUM FOLLOW-THROUGH STUDIES OF THE SMALL INTESTINE

The barium is mixed with individual sugars, and illustrates the dilution effect of osmotic diarrhoea (Laws and Neale, 1966). This test will no doubt be discussed in the next contribution. Its reliability in infancy is less and the extra radiation exposure unnecessary as simple stool tests as described will reveal similar information.

\section{Classification}

The specific disaccharidase enzyme deficiencies were the first to be recognized as a cause of persistent diarrhoea in children. The second cause to be recognized was the entity of glucose-galactose malabsorption. It was then realized that the disaccharidases and the mechanisms of transport of monosaccharides could be secondarily disturbed in many small-intestinal diseases (Table II) but particularly following gastroenteritis. Persistent diarrhoea in gastroenteritis is probably one of the commonest and most important clinical situations in which symptoms of sugar malabsorption are manifest. The primary disturbances are rare in comparison but important to identify because they can be so readily treated. I shall now deal individually with the various types of sugar malabsorption.

\author{
Post-gastroenteritis \\ Protein calorie malnutrition-kwashiorkor \\ Marasmus \\ Coeliac disease \\ Giardia lamblia infestation \\ Ulcerative colitis \\ Any other disorder of small-intestinal mucosa \\ Prematurity \\ Immunological deficiency diseases \\ In small infants \\ Gastrostomy \\ Ileostomy \\ Colostomy \\ Intestinal anastomosis-particularly in neonates
} Resection

Table II Conditions exhibiting secondary disaccharidase deficiencies

SUGAR MALABSORPTION DUE TO DISACCHARIDASE DEFICIENCIES

\section{Sucrase-isomaltase deficiency}

The first clinical description of malabsorption of sucrose was that of Weijers et al (1960) and then Auricchio, Prader, Mürset, and Witt (1961) described malabsorption of sucrose and maltose, particularly isomaltose. In 1962, Dr Messer, in my own department in Australia (Anderson et al, 1962), for the first time demonstrated by a qualitative chromatographic method the absence of sucrase and isomaltase activity in intestinal mucosa obtained by peroral biopsy from a baby with symptoms of sucrose malabsorption. Subsequently children and adults with this combined enzyme deficiency were reported from a number of countries and the condition was shown to be familial. Kerry and Townley (1966) investigated four families fully and demonstrated a recessive mode of inheritance; all parents and a proportion of siblings were found to have intestinal sucrase and isomaltase levels below the average found in the control group. It was considered that the ratio of lactase to sucrase was a better indication of the 


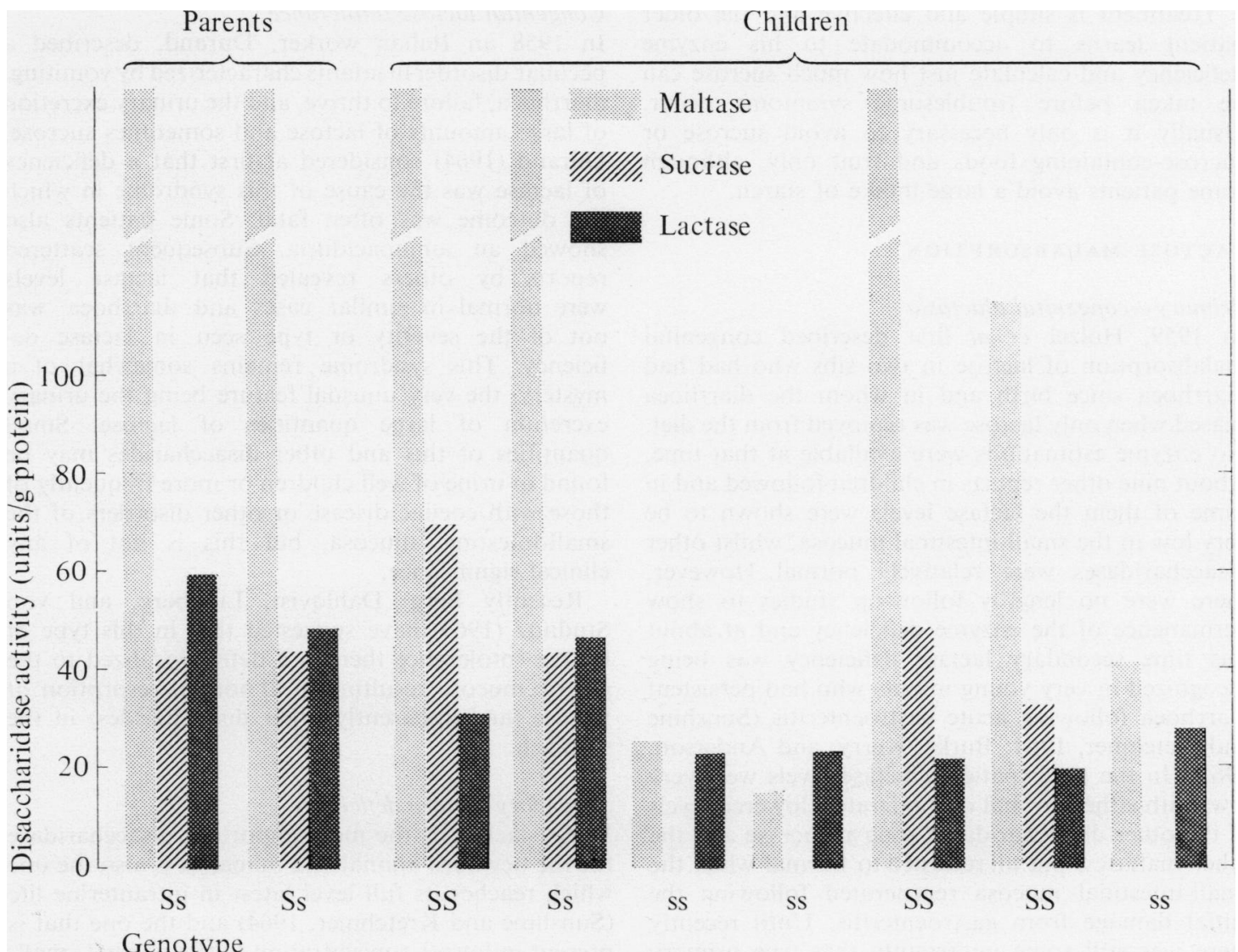

Fig. 1 A family with sucrase-isomaltese deficiency. Three patients are shown. The parents and one sibling recognized as heterozygotes by inverse ratio of sucrase to lactase; there were three normal sibs. Isomaltase results are not shown individually.

heterozygous state, ie, seven of eight parents had a lactase/sucrase ratio greater than $0 \cdot 8$. A representative family is indicated in Figure 1. Three children are affected: the parents and one of four sibs have levels of lactase higher than sucrase.

Sucrase-isomaltase deficiency is present at birth but symptoms are not manifest until sucrose is present in the diet. If the infant is breast fed the baby's diet does not include sucrose until mixed feeding is introduced, although fruit juices may stimulate diarrhoea. Some artificial milks may have sucrose added to them and in that case diarrhoea may be manifest from birth. Thus a detailed feeding history is essential and the simple therapeutic test of changing the diet to one that is sucrose-free should result in prompt cessation of the diarrhoea.

Isomaltose is not consumed as such, but during the digestion of starch isomaltase is concerned in the hydrolysis of maltotriose (Messer and Kerry,
1967). Although starch is usually well tolerated by these patients some may have mild symptoms related to its ingestion.

There is one rather strange feature of this combined enzyme deficiency. Although from examination of the intestinal mucosa its absence may appear to be complete, the symptoms vary in degree from individual to individual. They are more severe in the younger child than in the older one and certainly more severe than in the adult. In fact, patients with no symptoms have been observed, the diagnosis being made in the course of family studies (Kerry and Townley, 1965).

In the young child the symptom is responsible for fluid and electrolyte loss which may be accompanied by mild steatorrhoea from the intestinal hurry. Sometimes in an older child there may be only minor abdominal distension and failure to thrive together with some increase in the daily number of stools. 
Treatment is simple and effective and the older patient learns to accommodate to his enzyme deficiency and calculate just how much sucrose can be taken before troublesome symptoms occur. Usually it is only necessary to avoid sucrose or sucrose-containing foods and fruit only, although some patients avoid a large intake of starch.

\section{LACTOSE MALABSORPTION}

\section{Primary-congenital alactasia}

In 1959, Holzel et al first described congenital malabsorption of lactose in two sibs who had had diarrhoea since birth and in whom the diarrhoea ceased when only lactose was removed from the diet. No enzyme estimations were available at that time. About nine other reports in children followed and in some of them the lactase levels were shown to be very low in the small-intestinal mucosa, whilst other disaccharidases were relatively normal. However, there were no lengthy follow-up studies to show permanence of the enzyme deficiency and at about this time secondary lactase deficiency was being recognized in very young infants who had persistent diarrhoea following acute gastroenteritis (Sunshine and Ketchmer, 1964; Burke, Kerry, and Anderson, 1965). In the latter patients lactase levels were very low, with either normal or moderately lowered levels of the other disaccharidases, such as sucrase and the other maltases, but all returned to normal when the small-intestinal mucosa regenerated following the initial damage from gastroenteritis. Until recently there was still some uncertainty that true primary lactase deficiency from birth had been demonstrated. However, Levin, Abraham, Burgess, and Wallis (1970) have encountered a breast-fed infant who from the third day of life developed a severe watery diarrhoea which ceased abruptly when lactose was omitted from feeds and returned promptly when it was resumed and in whom lactase activity was virtually absent from the duodenal mucosa while maltase, isomaltase, and sucrase activities were quite normal. Histological appearances were normal. The child was still intolerant of lactose at $2 \frac{1}{2}$ years of age but was progressing normally on a lactosefree diet. A sibling had died earlier at $5 \frac{1}{2}$ months having had persistent diarrhoea since birth. The living child seems to fulfil all the criteria for a true primary congenital lactase deficiency. The condition seems very rare but there is no doubt that low lactase levels are common in the older child or adult, and the next paper will deal fully with this type of deficiency so I shall not elaborate on it here. Such persons must have normal levels in infancy as they do not show symptoms at that stage.

\section{Congenital lactose intolerance}

In 1958 an Italian worker, Durand, described a peculiar disorder in infants characterized by vomiting, diarrhoea, failure to thrive, and the urinary excretion of large amounts of lactose and sometimes sucrose. Durand (1964) considered at first that a deficiency of lactase was the cause of this syndrome in which the outcome was often fatal. Some patients also showed an aminoaciduria. Subsequent scattered reports by others revealed that lactase levels were normal in similar cases and diarrhoea was not of the severity or type seen in lactase deficiency. This syndrome remains somewhat of a mystery, the very unusual feature being the urinary excretion of large quantities of lactose. Small quantities of this and other disaccharides may be found in urine of well children or more frequently of those with coeliac disease or other disorders of the small-intestinal mucosa, but this is not of any clinical significance.

Recently Berg, Dahlqvist, Lindberg, and von Studnitz (1969) have suggested that in this type of lactose intolerance there is a defect localized to the gastric mucosa resulting in abnormal resorption of lactose (and apparently other disaccharides) in the stomach.

\section{Secondary lactase deficiency}

Whilst lactase is the most important disaccharidase for the newborn animal and human it is also the one which reaches its full level latest in intrauterine life (Sunshine and Kretchmer, 1964) and the one that is present in lowest concentration in the normal smallintestinal mucosa. As the disaccharidases are brush border enzymes they are readily diminished in any condition in which there is loss of normal mucosal epithelial cells, and lactase, because of its low initial levels and the large load of lactose taken by an infant in comparison with its size, is the one whose impairment is most frequently manifest as a clinical symptom. Few adults will consume 2 pints of milk per day but this is customarily imbibed by a baby aged 4 to 5 months, and often extra lactose is added to the feeds.

Table II lists the numerous situations which may be accompanied by symptoms of secondary lactase deficiency, and, if the mucosal damage is sufficient, by symptoms of sucrase deficiency as well. Starch or maltose intolerance is rarely clinically manifest as a secondary problem as the maltases, being the disaccharidases of highest activity, usually persist in sufficient quantity to cope with the starch and maltose loads.

In our society the commonest type of secondary lactase deficiency follows gastroenteritis of any type. If the small-intestinal mucosa is slow to repair so 
that the histological appearance remains abnormal, diarrhoea may persist when normal feeds are resumed after the initial restriction in the acute phase. The diarrhoea is recognized to be that of sugar intolerance by its watery nature, its acid $p \mathbf{H}$, and positive Clinitest. The institution of lactose-free milk feeds will bring about the cessation of symptoms and a subsequent weight gain. Sometimes all disaccharides must be withdrawn. Premature babies have lower lactase levels than full-term babies (Auricchio, Rubino, and Mürset, (1965) and early feeding of high calorie feeds, in which lactose may have been added to raise the calorie content, may precipitate diarrhoea. Prematurity plus gastroenteric infection is a potent cause of persistent diarrhoea from secondary lactose malabsorption. In underdeveloped countries kwashiorkor and malnutrition are commonly accompanied by lactase deficiency which is probably secondarily induced by repeated gastroenteric infections and poor nutrition (Bowie, Brinkman, and Hansen, 1965). Operations on the gastrointestinal tract in newborn or small infants are often followed by persistent diarrhoea which may be due to sugar intolerance. The infant who fails to gain weight and has stools with a fluid content causing excoriation around a colostomy may respond dramatically to a lactose-free milk feed. Patients with ileostomy or gastrostomy may be similarly affected, and gut resection with anastomosis is commonly followed by temporary sugar malabsorption and fluid diarrhoea (Burke and Anderson, 1966).

The abnormal mucosa obtained from the upper jejunum of a patient with coeliac disease will always show low disaccharidase levels, but only a very few patients show symptoms of sugar malabsorption as well as steatorrhoea. In a few patients the withdrawal of milk as well as gluten may be temporarily necessary but this should not be done on evidence of low disaccharidases in the biopsy only. In fact the determination of these enzymes as a routine in coeliac disease is not indicated.

\section{MALABSORPTION OF MONOSACCHARIDES}

The previous speaker has discussed something of the normal absorption of monosaccharides. There is no doubt that there are differences in the transport mechanisms of individual monosaccharides and until recently it was thought that although glucose and galactose were absorbed 'actively', ie, against a concentration gradient, fructose was not. Recent work (Gracey, Burke, and Oshin, 1970) shows fructose also to be actively transported although certainly not by the same carrier system. This difference is manifest in the clinical situation where a malabsorptive defect of only glucose and galactose exists in certain patients-in others all three are affected.

Primary congenital glucose-galactose malabsorption In 1962 two groups, the French workers (Laplane, Polonovski, Etienne, Debray, Lods, and Pissarro) and the Swedish workers (Lindquist and Meeuwisse) described infants in whom sugar diarrhoea occurred when feedings were first instituted after birth but in whom hydrolysis of the disaccharides appeared normal. These infants could not absorb glucose or galactose, but their diarrhoea ceased when fructose was the only carbohydrate in their feeds. The condition was shown to be familial, and there was some evidence that the transport defect was also present in the kidney. Within the next few years occasional families with this sugar transport defect were reported from a number of countries. Table III shows the absorptive problem affecting all sugars except fructose from a patient investigated by our own group. Other workers have gone on to show by autoradiographic studies the defective uptake of

\begin{tabular}{|c|c|c|c|}
\hline \multirow{2}{*}{$\begin{array}{l}\text { Sugar }(7 g \\
\text { Dose })\end{array}$} & \multicolumn{2}{|c|}{ Reducing Substances in Faeces } & \multirow{2}{*}{$\begin{array}{l}\text { Lactic Acid } \\
(m g) \text { in Faeces }\end{array}$} \\
\hline & Amount (g) & Type & \\
\hline Lactose & 3.9 & Glucose and galactose & 143 \\
\hline Sucrose & 1.5 & Glucose: trace of fructose & 320 \\
\hline Maltose & 3.9 & Glucose & 54 \\
\hline Glucose & $4 \cdot 1$ & Glucose & 42 \\
\hline Galactose & 2.6 & Galactose & 26 \\
\hline Fructose & Nil & Nil & 5 \\
\hline
\end{tabular}

Table III A patient with glucose-galactose malabsorption

glucose and galactose in the intestinal villi (Schneider, Kinter, and Stirling, 1966). This defect is an uncommon one, but treatment is effective and growth normal if all disaccharides containing glucose or galactose are excluded from the diet, and replaced by fructose. It is necessary in infancy to feed a milk which does not contain lactose or sucrose and one such-known as galactomin 19 (Trufood) which contains fructose-is commercially available. Gradually small amounts of starch are tolerated and, as the child grows, small quantities of milk or other substances containing glucose and galactose may be eaten, again by equating the intake against the production of diarrhoea.

As yet I know of no published account of an infant who developed fluid diarrhoea on ingesting fructose, although I have had a personal communication regarding a suspicious case from Norway. Fructose 
intolerance due to abnormality of the metabolism of fructose within the liver is an entirely different condition, being due to a defect of hepatic fructose1-phosphate splitting aldolase (Froesch, Wolf, Baitsch, Prader, and Labhart (1963).

\section{Secondary monosaccharide malabsorption}

In 1966, Burke and Danks published the records of several infants who suffered an acute gastroenteric illness in the early weeks of life, sometimes before leaving the maternity hospital. The diarrhoea persisted when normal feeds were resumed after initial restriction and the stools were numerous, fluid in consistency, and contained large amounts of reducing substances. No sugar, not even fructose, could be fed without stimulating diarrhoea which was life threatening. The condition gradually ameliorated and after weeks or months sugars could be tolerated. Recovery was usually complete. Others have since reported similar patients (Harries and Francis, 1968) and these workers have elaborated a synthetic sugarfree milk feed containing all necessary additives which can be given to such infants. Lifshitz, CoelloRamírez, and Gutíerrez-Topete (1970) have also shown complete monosaccharide malabsorption in association with malnutrition and gastroenteric infection in South America.

Gracey, Burke, and Anderson (1969) suggested from their findings that the sugar intolerance was one affecting the transport mechanisms of all monosaccharides and was associated with the presence of an abnormally profuse intestinal flora together with deconjugated bile salts in the upper small intestine. They coined the name 'contaminated small bowel' syndrome for this condition but offered no explanation for the presence of the flora, although they suggested that a more detailed examination of the flora than they had done might reveal anaerobic organisms that could be responsible for the deconjugation of bile salts. Gracey, Burke, Oshin, Barker, and Glasgow (1971) have recently described experiments in vivo and in vitro in blind-loop rats which show that deconjugated bile salts and an anaerobic flora are both present in that situation and the transport of monosaccharides is impaired in the gut proximal to the blind loop, in particular in the loop itself and to a much lesser extent in the immediately distal gut. Experiments in vitro with rat gut segments using the Semenza and Mühlhaupt technique(1969) also demonstrated reversible impairment of arbutin (a non-metabolized glucose analogue) uptake when deconjugated bile salts were present in the incubation medium (Gracey, Burke, and Oshin, 1971). It still remains to confirm the association of flora and deconjugated bile salts in the infant clinical situation of monosaccharide malabsorption, a problem we are currently investigating.

\section{Summary}

It can thus be seen that digesting and absorbing mechanisms for sugar in the gut can be readily upset, and depending on exposure to dietary sugars and their load, osmotic diarrhoea will result. Whilst genetically determined errors of development of both disaccharidase enzymes and of monosaccharide transport mechanisms have been clearly delineated, there is also a wide range of secondary disturbances based both on destruction of the integrity of the mucosal epithelial cells and their brush border but also on alteration of conditions within the lumen of the gut. The secondary disturbances are of much greater frequency in clinical practice than the primary disorders and their recognition and understanding will lead to a decrease in morbidity and prolonged hospitalization and debility in many patients, particularly following acute gastroenteritis or surgical operations on the gut, especially in the newborn period. We have noted sugar diarrhoea following neonatal gut anastomosis, resection, colostomy, ileostomy, and even gastrostomy (Burke and Anderson, 1966). This may varyo from just disaccharide intolerance to complete monosaccharide intolerance. An understanding of the disturbances of the absorbing mechanisms of sugar following gut surgery would be of assistance in the postoperative management of such patients.

The development of the technique of peroral intestinal mucosal biopsy has been of great value in the understanding of the different types of sugar malabsorption, particularly those of primary genetic origin. However, the presence of sugar intolerance may be easily diagnosed by simpler tests, and intestinal biopsy followed by estimation of mucosal disaccharides is rarely necessary in the diagnosis and management of secondary sugar intolerance.

\section{References}

Anderson, C. M., Messer, M., Townley, R. R. W., Freeman, M., and Robinson, M. J. (1962). Intestinal isomaltase deficiency in patients with hereditary sucrose and starch intolerance. (Letter.) Lancet, 2, 556-557.

Auricchio, S., Prader, A., Mürset, G., and Witt, G. (1961). Saccharoseintoleranz. Durchfall infolge heredităren Mangels an intestinaler Saccharaseaktivität. Helv. paediat. Acta, 16, 483505.

Auricchio, S., Rubino, A., and Mürset, G. (1965). Intestinal glycosidase activities in the human embryo, fetus, and newborn. Pediatrics, 35, 944-954.

Berg, N. O., Dahlqvist, A., Lindberg, T, and Studnitz, W, von. (1969) Severe familial lactose intolerance-a gastrogen disorder? Acta paediat. scand., 58, 525-527.

Bowie, M. D., Brinkman, G. L., and Hansen, J. D. L. (1965). Acquired disaccharide intolerance in malnutrition. J. Pediat., 66, 1083-1091. 
Burke, V., and Anderson, C. M. (1966). Sugar intolerance as a cause of protracted diarrhoea following surgery of the gastrointestinal tract in neonates. Aust. paediat. J., 2, 219-227.

Burke, V., and Danks, D. M. (1966). Monosaccharide malabsorption in young infants. Lancet, 1, 1177-1180.

Burke, V., Kerry, K. R., and Anderson, C. M. (1965). The relationship of dietary lactose to refractory diarrhoea in infancy. Aust. paediat. J., 1, 147-160.

Dahlqvist, A. (1964). Method for assay of intestinal disaccharidases. Analyt. Biochem., 7, 18-25.

Durand, P. (1958). Lattosuria idiopatica in una paziente con diarrea cronica ed acidosi. Minerva pediat., 10, 706-711.

Durand, P. (1964). Lactose intolerance. In Disorders Due to Intestinal Defective Carbohydrate Digestion and Absorption, edited by P. Durand, p. 105. Il Pensiero Scientifico, Rome.

Froesch, E. R., Wolf, H. P., Baitsch, H., Prader, A., and Labhart, A. (1963). Hereditary fructose intolerance. An inborn defect of hepatic fructose-1-phosphate splitting aldolase. Amer. J. Med., 34, 151-167.

Gracey, M., Burke, V., and Anderson, C. M. (1969). Association of monosaccharide malabsorption with abnormal small-intestinal flora. Lancet, 2, 384-385.

Gracey, M., Burke, V. and Oshin, A. (1970). Intestinal transport of fructose. (Letter.) Lancet, 2, 827-828.

Gracey, M., Burke, V., and Oshin, A. (1971). Reversible inhibition of intestinal active sugar transport by deconjugated bile salts in vitro. Biochim. biophys. Acta. (Amst.), 225, 308-314.

Gracey, M., Burke, V., Oshin, A., Barker, J., and Glasgow, E. (1971). Bacteria, bile salts and intestinal monosaccharide malabsorption. Gut. (In the press.)

Harries, J. T., and Francis, D. E. M. (1968). Temporary monosaccharide intolerance. Acta paediat. scand., 57, 505-511.

Holzel, A., Schwarz, V., and Sutcliffe, K. W. (1959). Defective lactose absorption causing malnutrition in infancy. Lancet, 1, 11261128.

Howland, J. (1921). Prolonged intolerance to carbohydrates. Trans. Amer. pediat. Soc. (N.Y.) 38, 393-396.

Kerry, K. R., and Anderson, C. M. (1964). A ward test for sugar in faeces. Lancet, 1, 981-982.

Kerry, K. R., and Townley, R. R. W. (1965). Genetic aspects of intestinal sucrase-isomaltase deficiency. Aust. paediat. J., 1, 223-235.

Laplane, R., Polonovski, C., Etienne, M., Debray, P., Lods, J-C., and Pissarro, B. (1962). L'intolérance aux sucres à tranfert intestinal actif. (Ses rapports avec l'intolérance au lactose et le syndrom coeliaque). Arch. franc. Pediat., 19, 895-944.

Laws, J. W., and Neale, G. (1966). Radiological diagnosis of disaccharidase deficiency. Lancet, 2, 139-143.

Levin, B., Abraham, J. M., Burgess, E. A., and Wallis, P. G. (1970). Congenital lactose malabsorption. Arch. Dis. Childh., 45, 173-177.

Lifshitz, F., Coello-Ramirez, P., and Gutíerrez-Topete, G. (1970). Monosaccharide intolerance and hypoglycemia in infants with diarrhea. I Clinical course of 23 infants. J. Pediat., 77, 595-603.

Lindquist, B., and Meeuwisse, G. W. (1962). Chronic diarrhoea caused by monosaccharide malabsorption. Acta paediat. scand., 51, 674-685.

Messer, M., and Dahlqvist, A. (1966). A one-step ultramicro method for the assay of intestinal disaccharidases. Analyt. Biochem., 14, 376-392.

Messer, M., and Kerry, K. R. (1967). Intestinal digestion of maltotriose in man. Biochim. biophys. Acta (Amst.), 132, 432-443.

Schneider, A. J., Kinter, W. B., and Stirling, C. E. (1966). Glucosegalactose malabsorption. Report of a case with autoradiographic studies of a mucosal biopsy. New Engl. J. Med., 274, 305-312.

Semenza, G., and Mühlhaupt, E. (1969). Studies on intestinal sucrase and sugar transport. VII $A$ method for measuring intestinal uptake. The absorption of the anomeric forms of some monosaccharides. Biochim. biophys. Acta (Amst.), 173, 104-112.

Sunshine, P., and Kretchmer, N. (1964). Studies of small intestine during development. III Infantile diarrhea associated with intolerance to disaccharides. Pediatrics, 34, 38-50.

Weijers, H. A., Kamer, J. H. van de, Dicke, W. K., and Ijsseling, J. (1961). Diarrhoea caused by deficiency of sugar-splitting enzymes. Acta paediat. (Uppsala), 50, 55-71.

Weijers, H. A., Kamer, J. H. van de, Mossel, D. A. A., and Dicke, W. (1960). Diarrhoea caused by deficiency of sugar-splitting enzymes. Lancet, 2, 296-297. 